\title{
Bundle-branch Block in Acute Myocardial Infarction
}

\author{
DAVID HUNT,* M.D., M.R.A.C.P. ; GRAEME SLOMAN, † M.B., F.R.C.P.ED., F.R.A.C.P.
}

Brit. med. F., 1969, 1, 85-88

Summary : Bundle-branch block was present in 41 out of 415 patients admitted to a coronary care unit with acute myocardial infarction and was associated with more severe clinical infarction and an overall mortality of $56 \%$. It is probable that permanent bundle-branch block develops soon after infarction and that most of the patients with permanent block have had clinically severe infarction. Bundle-branch block developing during observation is usually transient, and the later it develops the sooner it resolves.

Analysis of the arrhythmias and clinical course of the patients suggests that those with bundle-branch block and shock and those in whom bundle-branch block is present on admission may benefit from the use of a demand pacemaker attached to a transvenous pacemaker catheter, though the dividends of pacing may be small and the risks of the procedure significant. Post-mortem examination of 17 hearts showed extensive infarction, usually involving the septum, and severe coronary artery disease.

\section{Introduction}

Bundle-branch block in acute myocardial infarction is generally associated with a poor prognosis. We here review our experiences with 41 patients with bundle-branch block who have been treated in the coronary care ward at the Royal Melbourne Hospital.

\section{Clinical Material}

Since February 1963, 415 patients with acute myocardial infarction have been admitted to our unit. The patient's condition on admission was classified as mild, severe, or cardiogenic shock (Robinson et al., 1964). Those admitted after successful resuscitation have been grouped with the shock patients. Zero time was taken as the time of onset of severe or persistent pain. Details of the unit and management of the
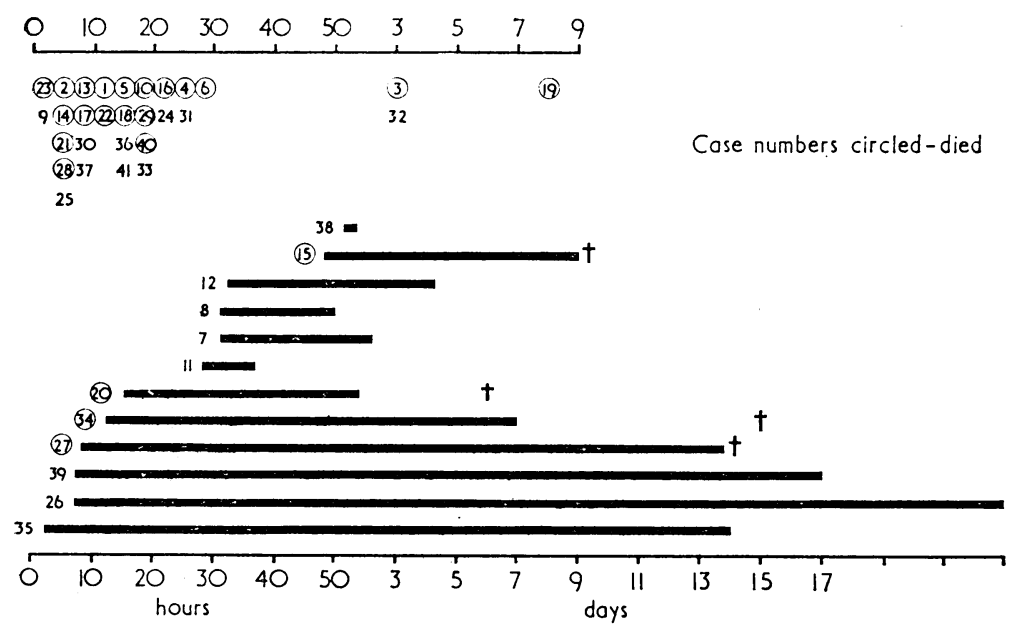

Fig. 1.- Case numbers are shown. Circled numbers indicate that patient died within six weeks of infarction. The block of patients in the upper area was present on admission. The time of onset and duration of block in those in whom it developed while under observation are shown in the lower area. patients are given elsewhere (Robinson et al., 1964). A 10second strip of electrocardiographic recording was made every half-hour, or more often if arrhythmias were seen on the monitoring oscilloscope. Unless complications developed the patients were discharged from the coronary care unit to a general medical ward after 72 hours. The survivors were reviewed six weeks after the onset of infarction.

The Minnesota code criteria of bundle-branch block (Rose and Blackburn, 1968) were used.

\section{Resulis}

Table I shows the clinical features of the 41 patients, classified according to type of bundle-branch block and severity of infarction.

Table II compares the mortality figures for the 41 patients with bundle-branch block with those of our total of 415 patients classified according to severity of infarction.

Fig. 1 shows the time at which bundle-branch block was first detected and its duration. Bundle-branch block was present on admission in 29 patients and developed during observation in the other 12 .

Six patients had had an electrocardiogram taken within the month preceding acute infarction. Case 4 was known to have had left bundle-branch block for four years, Case 41 had right bundle-branch block, but Cases 3, 17, 19, and 22 all had normal conduction. All these patients, except Case 41, died within six weeks of infarction.

Twenty-three patients died in hospital, and in 17 of them necropsy was carried out. Infarction was present in the anterior wall of the left ventricle in 13 hearts, in the posterior wall in 10 , and in the interventricular septum in 16. Every heart except one (Case 10) showed extensive coronary artery disease involving all three vessels. Only one heart weighed less than $400 \mathrm{~g}$. (Case 29) ; nine hearts weighed over $500 \mathrm{~g}$. The average weight of the hearts with left bundle-branch block was 550 g., and of those with right bundle-branch block 489 g., but this difference is not statistically significant ( $P>0.05$, nonpaired $t$ test). The average weight of the hearts of 23 patients who died in our overall coronary care series following acute myocardial infarction unassociated with bundle-branch block was $487 \mathrm{~g}$., and this finding is not significantly different from the weights of the hearts associated with either left or right bundle-branch block.

All survivors were traced (Fig. 2). Fourteen patients were still alive at from 2 to 55 months after infarction, while four had died-one (Case 36) died in cardiac failure at 12 months, one (Case 8) died suddenly at home at 12 months, one (Case 39) had persistent cardiac failure and died with further chest pain and ventricular fibrillation, and one (Case 24) died at 24 months, no details being available. In none of these four patients had a necropsy been carried out.

* National Heart Foundation Research Assistant in receipt of Grant-in-Aid G524/428.

t Director of the Cardiac Laboratory, Department of Cardiology, Royal Melbourne Hospital, Melbourne, Australia. 
TABLE I.-Clinical Features of 41 Patients with Bundle-Branch Block and Acute Myocardial Infarction

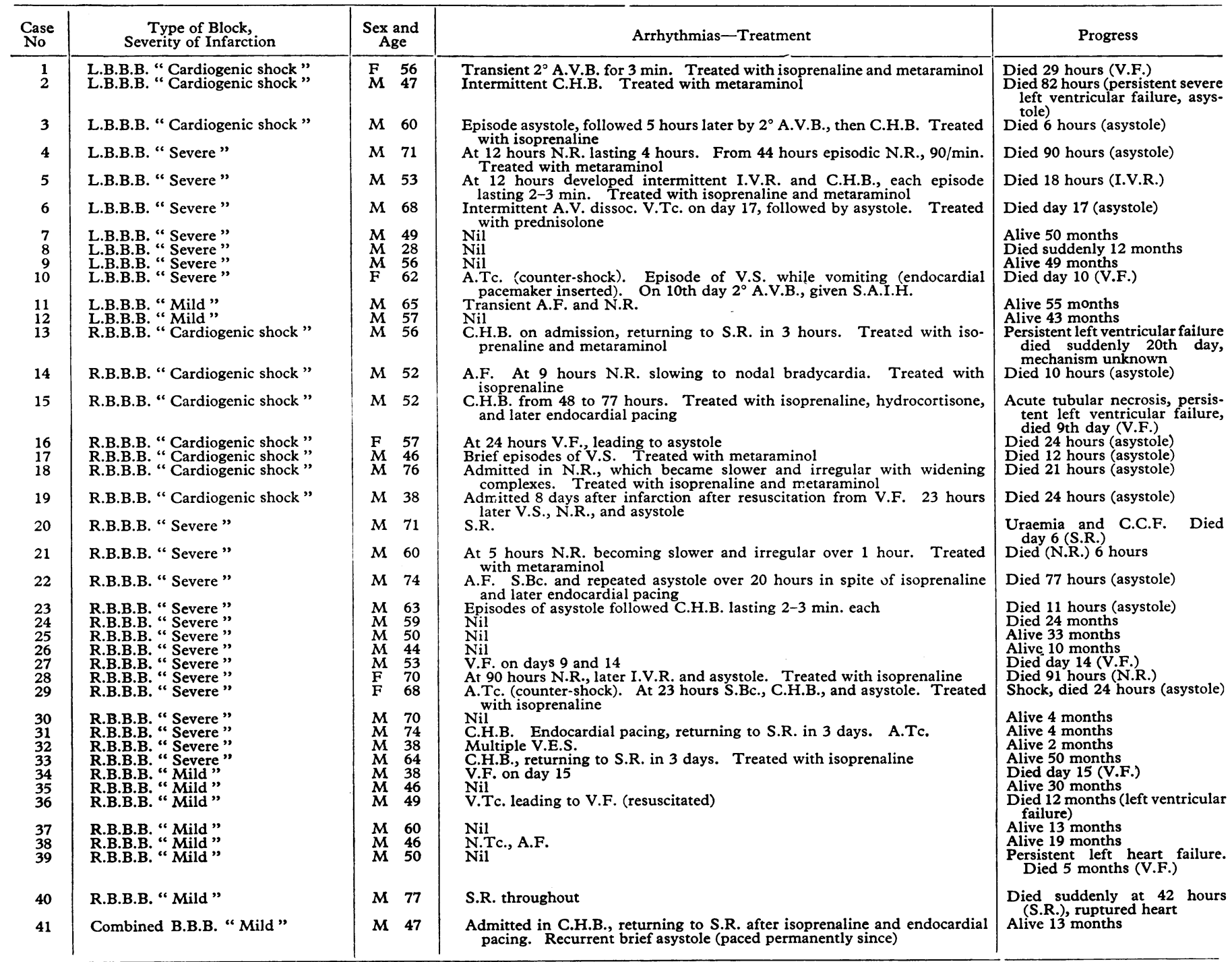

L.B.B.B. $=$ Left bundle-branch block. R.B.B.B. $=$ Right bundle-branch block. A.F. $=$ Atrial fibrillation. A.Tc. $=$ Atrial tachycardia. $2^{\bullet}$ A.V.B. $=$ Second

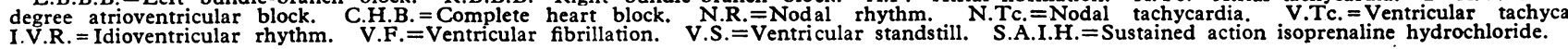

\section{Discussion}

The incidence of bundle-branch block in acute infarction varies from $7.8 \%$ (Imperial et al., 1960) to $13 \%$ (Bauer et al., 1965); in our series it was $10 \%$ of 415 patients. Among

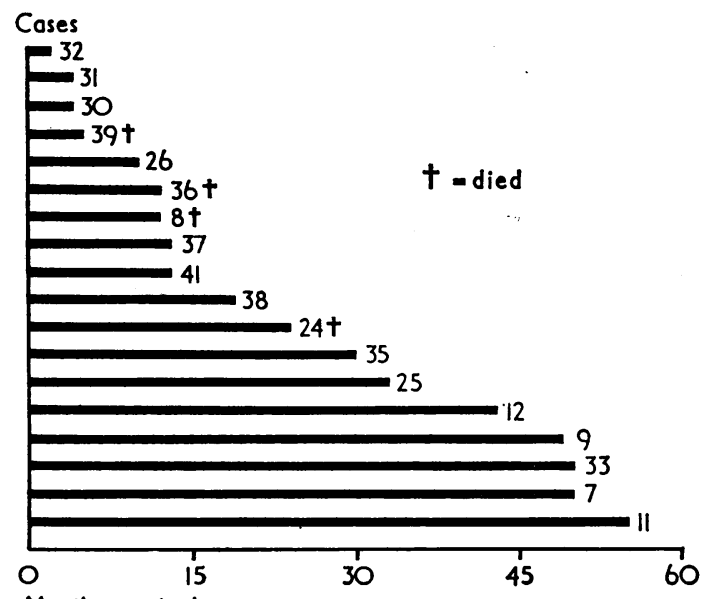

Months survival

Fig. 2.-Follow-up of patients surving longer than six weeks from acute infarction. our patients right bundle-branch block was more than twice as frequent as left bundle-branch block. Imperial et al. (1960) found 12 cases of right bundle-branch block and none with left bundle-branch block among 153 patients with acute infarction ; but in the series reported by Hipp et al. (1961) and Bauer et al. (1965) the incidence of right and left bundlebranch block was about equal. Right bundle-branch block is more common than left bundle-branch block, probably because the right bundle is a long slender discrete structure, vulnerable to damage by small areas of infarction, whereas the left bundle divides early, and therefore a larger area of damage is necessary to cause block. However, the mortality of right and left bundle-branch block in our series is strikingly similar (Table II).

Bundle-branch block is associated with a poor prognosis in acute myocardial infarction. Imperial et al. (1960) found a mortality of $50 \%$ in patients with infarction and right bundlebranch block, and Hipp et al. (1961) found that 52\% of men with a first infarction and persistent bundle-branch block died within two months of infarction. The overall mortality for bundle-branch block associated with myocardial infarction varies from 32\% (Mintz and Katz, 1947) to 62\% (Bauer et al., 1965). Fifty-six per cent. of our patients with bundle-branch block died, compared with $26 \%$ of our overall series with acute infarction (Table II). 
TABLE II.-Mortality after Acute Myocardial Infarction

\begin{tabular}{|c|c|c|c|c|c|c|c|c|c|}
\hline & & \multicolumn{2}{|c|}{ All Cases } & \multicolumn{2}{|c|}{ L.B.B.B. } & \multicolumn{2}{|c|}{ R.B.B.B. } & \multicolumn{2}{|c|}{ Overall B.B.B. (including Combined) } \\
\hline & & No. & Mort. & No. & Mort. & No. & Mort. & No. & Mort. \\
\hline $\begin{array}{l}\text { Mild } \quad \cdots \quad \ldots \\
\text { Severe } \\
\text { Cardiogenic shock }\end{array}$ & $\begin{array}{l}. \\
\therefore\end{array}$ & $\begin{array}{r}186(45 \%) \\
163(39 \%) \\
66(16 \%)\end{array}$ & $\begin{array}{l}17(9 \%) \\
47(29 \%) \\
44(67 \%)\end{array}$ & $\begin{array}{l}2(17 \%) \\
7(58 \%) \\
3(25 \%)\end{array}$ & $\begin{array}{l}0(0 \%) \\
4(57 \%) \\
3(100 \%)\end{array}$ & $\begin{array}{r}7(25 \%) \\
14(50 \%) \\
7(25 \%)\end{array}$ & $\begin{array}{l}2(28 \%) \\
7(50 \%) \\
7(100 \%)\end{array}$ & $\begin{array}{l}10(24 \%) \\
21(52 \%) \\
10(24 \%)\end{array}$ & $\begin{array}{c}2(20 \%) \\
11(52 \%) \\
10(100 \%)\end{array}$ \\
\hline Total & $\ldots$ & 415 & $108(26 \%)$ & 12 & $7(58 \%)$ & .28 & $16(57 \%)$ & 41 & $23(56 \%)$ \\
\hline
\end{tabular}

Among our 41 patients there was a decreased percentage of cases in the mild group and an increased percentage in the severe and shock groups compared with our overall series (Table II). Mintz and Katz (1947), Hipp et al. (1961), and Bauer et al. (1965) also found bundle-branch block to be relatively more common in clinically severe infarction. This alone does not explain the increased mortality rate associated with bundle-branch block; for it can be seen from Table II that the mortality in each clinical group of severity is increased in this condition. There are fewer patients in the mild group, as bundle-branch block is associated with more extensive infarction. This is borne out by the pathological studies. Electrocardiography showed that anterior, septal, and posterior infarction were present in $83 \%, 62 \%$, and $25 \%$ of our cases respectively, and the incidence at each site was even more common at necropsy, septal involvement being present in $94 \%$ of hearts. The mechanism of production of bundle-branch block in the patients without septal involvement is probably due to involvement of the peripheral conducting system.

Of the 29 patients who had bundle-branch block when first seen, 19 died, but death occurred in only 4 out of the 12 who developed block during observation. In this latter group only one (Case 15, cardiogenic shock) of the six patients who developed block later than 20 hours from infarction died, while three of the six who developed block within 20 hours died, suggesting that the earlier onset of block is associated with a worse prognosis.

The permanency of the block also seems to depend on its time of onset. None of the five survivors of the group observed to develop block later than 20 hours had permanent block, but this occurred in 9 of the 11 in whom it was present within 20 hours of infarction. The block was permanent in all the survivors of those with block present on admission and yet in only one of the three survivors of those in whom it was observed to develop within eight hours of infarction; this suggests that those who develop permanent block do so either at or soon after the onset of acute infarction. It is possible that the block was present before infarction, as was known in two cases. It can also be seen (Fig. 1) that block developing after 20 hours resolved more rapidly than when it developed within 20 hours of infarction.

\section{Long-term Follow-up}

Among our 18 survivors to six weeks there were nine with permanent right bundle-branch block, one with permanent left bundle-branch block, and one with bilateral bundle-branch block. Hipp et al. (1961) reported that 5 out of 23 cases with permanent bundle-branch block survived for five years after infarction. Four (two with permanent right bundle-branch block) of our 18 survivors to six weeks have since died, three of them within a year of infarction, and though four patients have not yet been followed for 12 months the one-year mortality is already $12 \%$. Denborough et al. (1968), in a series of 412 patients with acute myocardial infarction who survived to leave hospital, reported a similar mortality at one year.

Seven of the 11 survivors to six weeks with permanent bundle-branch block had had severe infarction, and the block in one (Case 41) of the other four was known to have been present before infarction. Permanent bundle-branch block occurred in only three out of eight patients (including Case 41) with mild infarction, but in 8 out of 10 with severe infarction. Thus permanent bundle-branch block is more likely after severe than after mild infarction.

Among our patients who died, advanced atrioventricular block, nodal rhythm, ventricular standstill, and episodes of asystole were common. Among the 18 survivors, three were admitted in complete heart block, one developed ventricular tachycardia leading to ventricular fibrillation, and three developed supraventricular arrhythmias. Recurrent arrhythmias were more common in the group with bundle-branch block present on admission compared with the group in which bundlebranch block developed during observation.

\section{Indications for Transvenous Pacemakers}

Lassers and Julian (1968) reported 29 cases of complete heart block developing after admission, and 16 of these were preceded by bundle-branch block. Godman et al. (1968) suggested that $25 \%$ of patients with complete bundle-branch block progress to complete heart block, and this led Lassers and Julian (1968) to conclude that it was advisable to insert transvenous pacemaker catheters into all patients with bundle-branch block. Epstein et al. (1966) reached a similar conclusion. Our four patients with complete heart block on admission all returned to sinus rhythm, though one man (Case 41) had recurrent episodes of asystole which necessitated permanent cardiac pacing. Of our other 37 patients, one developed atrioventricular dissociation and six developed complete heart block, though in two of these the block occurred during the final pattern of arrhythmias preceding death.

Analysis of our figures suggests that a case can be made for the insertion of transvenous endocardial pacemaker catheters connected to demand pacemaker units into patients with severe infarction and bundle-branch block present on admission and into patients with bundle-branch block and shock. The results of pacing these patients is not at present known, but it may well be that little benefit will occur ; in fact, one of our patients (Case 22) died in spite of endocardial pacing. Epstein et al. (1966) reported the results of endocardial pacing in 10 cases of complete heart block complicating acute myocardial infarction, five of whom were admitted in sinus rhythm with bundlebranch block. Four of these five patients had left ventricular failure and one had cardiogenic shock, and all five developed advanced atrioventricular block. Pacing was begun when standard medical therapy had been of no value. One did not respond at all. The other four improved in their general condition but left ventricular failure persisted, two dying within 24 hours and the other two within two months. The actual insertion of a transvenous catheter is not without risk, and this may outweigh any benefit from pacing. The complications attending insertion of endocardial pacemaker catheters are well known and include ventricular fibrillation. These complications are more likely to occur in patients with more severe infarction or shock.

At necropsy the hearts of our patients with bundle-branch block were significantly heavier than normal, signifying the presence of chronic heart disease, but they were no heavier than the hearts of other patients from our coronary care unit who did not have bundle-branch block. Hipp et al. (1961) found large transmural infarcts and complete occlusion of one major 
coronary artery in each case, and marked cardiac enlargement in seven out of eight men with persistent bundle-branch block who died within two months of their first infarction. When advanced surgical techniques become available to patients with acute myocardial infarction it is unlikely that any procedure short of replacement of the heart will benefit patients with bundle-branch block because of the extensive infarction usually involving the septum, severe coronary artery disease, and evidence of cardiac hypertrophy.

We wish to thank the physicians of the Royal Melbourne Hospital for permission to study cases under their care.

\section{REFERENCES}

Bauer, G. E., Julian, D. G., and Valentine, P. A. (1965). Brit. Heart J. 27,724 .

Denborough, M. A., Lovell, R. R. H., Nestel, P. J., and Goble, A. J. (1968). Lancet, 1, 386.

Epstein, E. J., Coulshed, N., McKendrick, C. S., Clarke, J., and Kearns, W. E. (1966). Brit. Heart ₹., 28, 546

Godman, M. J., Lassers, B. W., and Julian, D. G. (1968). In preparation. Hipp, H. R., Beard, O. W., Taylor, J. S., Ebert, R. V., and Robins, M. (1961).' Amer. Heart f̈., 62, 43 . Imperial, E. S., Carballo R., and Zimmerman, H. A. (1960). Amer. Y.

Lassers, B. W., and Julian, D. G. (1968). Brit. med. 7., 2, 142

Mintz, S. S., and Katz, L. N. (1947). Arch. intern. Med., 80, 205.

Robinson, J. S., Sloman, G., and McRae, C. (1964). Med. F. Aust., 1, 427. Rose, G. A., and Blackburn, H. (1968). Wld Hlth Org. Monogr. Ser.,
No. 56.

\title{
Plasminogen-activator-producing Tumour
}

\author{
J. F. DAVIDSON,* M.B., M.R.C.P.BD. ; G. P. MCNICOL, $\dagger$ M.D., PH.D., F.R.C.P.ED., F.R.C.P.GLASG. \\ G. L. FRANK, $\ddagger$ M.B., M.C.PATH.; T. J. ANDERSON,§ M.B., СH.B. \\ A. S. DOUGLAS, $\|$ M.D., F.R.C.P., F.R.C.P.ED., F.R.C.P.GLASG.
}

Brit. med. F., 1969, 1, 88-91

\begin{abstract}
Summary : In a patient with giant-cell carcinoma of the lung a secondary tumour deposit in the arm was incised and bled for three weeks. Investigations showed the tumour to be rich in plasminogen activator. Haemostasis in the tumour was achieved with aminocaproic acid therapy. For a period the plasminogen-activator properties were retained in cell culture of the tumour.
\end{abstract}

\section{Introduction}

Malignant disease, particularly disseminated carcinoma, may be complicated by a haemostatic defect which can arise during the course of the disease or during surgery. This can take the form of disseminated intravascular coagulation or pathological fibrinolysis. Elucidation of the pathogenesis is important in view of the different mechanisms which require different therapeutic measures. Straub, Riedler, and Frick (1967) reported disseminated intravascular coagulation with hypofibrinogenaemia and secondary fibrinolysis in a case of generalized prostatic carcinoma which responded to heparin therapy. Tagnon, Schulman, Whitmore, and Leone (1953) found pathological fibrinolysis in a prostatic carcinoma and evidence of proteolytic activity in a bone metastasis. Hormonal therapy directed against the tumour produced remission both of the tumour and of the fibrinolytic state.

According to current concepts (McKay, 1965 ; Straub et al., 1967) the defibrination syndrome found in malignant disease is usually caused by disseminated intravascular coagulation. Certain cases remain, however, in which this is not a satisfactory explanation, and where investigation indicates primary pathological fibrinolysis as the pathogenetic mechanism.

In this report the findings are recorded in a patient with a secondary carcinoma of the arm which when incised developed

\footnotetext{
* Senior Registrar in Haematology, Glasgow Royal Infirmary. + Senior Lecturer in Medicine, Glasgow Royal Infirmary. ‡Consultant in Laboratory Medicine, Glasgow Royal Infirmary. Registrar in Laboratory Medicine, Glasgow Royal Infirmary. Present address, Department of Biochemistry, Glasgow University. 11 Professor of Medicine, Glasgow Royal Infirmary.
}

a localized haemostatic defect without systemic abnormality. So far as we are aware this is the first reported case of a plasminogen-activator-producing tumour with localized defective tumour haemostasis.

\section{Case Report}

A 71-year-old housewife presented at the casualty department in May 1967 with a three-weeks history of pain in the left forearm and difficulty in extending the fingers. Her previous health had been good, and there was no systemic upset.

On examination a warm indurated swelling of the flexor aspect of the left forearm with some surrounding induration was found. One small lymph node was palpable in the left axilla. There was stiffness of the fingers. Physical examination was otherwise unremarkable.

A diagnosis of cellulitis of the forearm was made and penicillin given. After seven days there was no improvement, so the swelling was incised and explored. Only sterile serosanguineous material was obtained, and no pus was found. Ten days later, when the swelling and tenderness were extending proximally, a second incision was made, and again only sterile serosanguineous material was obtained.

The first wound bled steadily for 10 days and the second for 27 days until aminocaproic acid was given (see below). The severity of the blood loss from the arm was indicated by a fall in haemoglobin level from 13.6 to $7.6 \mathrm{~g} . / 100 \mathrm{ml}$. in 14 days. Thereafter only by the transfusion of six bottles of blood over a period of 10 days was a further fall prevented. There was no bleeding from any other site to account for the falling haemoglobin.

When bleeding from the second incision had continued steadily for 10 days it became obvious that there was a defect in haemostasis at the site of the arm swelling, and coagulation and fibrinolytic investigations were undertaken. These are described in detail below.

Despite supportive measures and blood transfusion the patient's general condition deteriorated gradually. Wound fluid was readily obtained by aspiration from the incision, and cytological and histological examination showed it to contain many undifferentiated and poorly differentiated malignant cells. Despite an exhaustive search no primary tumour site was found in life. Radiological studies of the forearm, including angiography, showed no evidence of tumour circulation or bone involvement. 